\title{
EMILIA PARDO BAZÁN, LAS MUJERES Y LA EDUCACIÓN. EL CONGRESO PEDAGÓGICO (1892) Y LA CÁTEDRA DE LITERATURA (1916)
}

\author{
Emilia Pardo Bazán, women and education. The Pedagogical \\ Conference (1892) and the Chair of Literature (1916)
}

\author{
Narciso de Gabriel*
}

Fecha de recepción: 11/12/2017 • Fecha de aceptación: 16/01/2018

Resumen. En la trayectoria de Emilia Pardo Bazán se percibe una preocupación persistente por los problemas educativos, especialmente los relacionados con las mujeres. Su intervención en el Congreso Pedagógico Hispano-Portugués-Americano (1892) supuso una inflexión en la forma de entender en España la educación de las mujeres. La primera parte de este artículo está dedicada al análisis de su ponencia, los debates que suscitó entre los congresistas y las repercusiones que tuvo en la prensa. En la segunda parte centraremos nuestra atención en la decisión del ministro Julio Burell de crear una cátedra de Literatura Contemporánea de las Lenguas neo-latinas, destinada a la escritora gallega, en el doctorado de la Facultad de Filosofía y Letras de la Universidad Central (1916). La adjudicación de la cátedra se realizaría mediante el procedimiento extraordinario regulado en la Ley Moyano, pero la candidata no obtuvo el apoyo de dos de las tres instancias llamadas a pronunciarse: la Real Academia Española y la propia Facultad de Filosofía y Letras. Solamente votó a favor el Consejo de Instrucción pública, del que ella formaba parte. A pesar de estas resistencias, el ministro siguió adelante con la propuesta y convirtió a doña Emilia en catedrática.

Palabras clave: Emilia Pardo Bazán; Congreso Pedagógico de 1892; Educación de las mujeres; Profesoras universitarias; Feminismo

Abstract. Over the course of her career, Emilia Pardo Bazán always had a con-
tinuing concern for educational issues, particularly as they related to
women. Her participation in the Hispano-Portuguese-American Pedago-

\footnotetext{
* Departamento de Pedagogía y Didáctica, Facultad de Ciencias de la Educación, Universidade da Coruña, Campus de Elviña s/n, 15071 A Coruña. España. narciso.de.gabriel@udc.es
}

Cómo citar este artículo: Gabriel, Narciso de. «Emilia Pardo Bazán, las mujeres y la educación. El Congreso Pedagógico (1892) y la Cátedra de Literatura (1916)». Historia y Memoria de la Educación 8 (2018): 489-525. 
gical Conference (1892) marked a turning point in the way women's education was seen in Spain. The first part of this article presents an analysis of her lecture, the ensuing discussions among the participants and the repercussions it had in the press. In the second part, we have focused on minister Julio Burell's decision to institute a professorship of Modern Literature in Neo-Latin languages, which was designed for the Galician writer, in the doctoral programme of the School of Philosophy and Liberal Arts at the Central University (1916). The professorship was to be awarded by means of an extraordinary procedure as regulated in the Moyano Act, but the candidate did not receive the support of two of the three institutions called upon to decide: the Royal Spanish Academy and the School of Philosophy and Liberal Arts. The only vote in favour came from the Council of Public Instruction, where she was a member. Despite this resistance, the minister went ahead with the proposal and awarded Doña Emilia the professorship.

Keywords: Emilia Pardo Bazán; Pedagogical Conference of 1892; Women's education; University professors; Feminism

A diferencia de una de sus bisabuelas, que se vio obligada a aprender a escribir en solitario, utilizando como pluma un palo aguzado y como tinta zumo de moras, Emilia Pardo Bazán (A Coruña, 1851-Madrid, 1921) tuvo el decidido apoyo de sus padres para iniciarse en el mundo de la lectura y la escritura. ${ }^{1}$ Amalia de la Rúa y José Pardo Bazán, ambos de estirpe hidalga, se ocuparon personalmente de la educación de su única hija, contrataron a profesores para que la instruyesen en determinadas materias, la enviaron a un colegio francés durante la estancia de la familia en Madrid y pusieron a su disposición una bien surtida biblioteca, además de proporcionarle el acceso a las de sus amistades. ${ }^{2}$ Andando el tiempo, también se beneficiará de las orientaciones que le proporcionará, entre otras personalidades, Francisco Giner de los Ríos. ${ }^{3}$ En todo

\footnotetext{
${ }^{1}$ Agradezco a la profesora Patricia Carballal sus sugerencias y aportaciones para la realización de este trabajo y sus observaciones sobre el texto final.

${ }^{2}$ Entre las biografías de nuestra protagonista citaremos las realizadas por Carmen Bravo-Villasante, Vida y obra de Emilia Pardo Bazán (Madrid: Magisterio Español, 1973); Pilar Faus, Emilia Pardo Bazán. Su época, su vida, su obra (A Coruña: Fundación Pedro Barrié de la Maza, 2003); Eva Acosta, Emilia Pardo Bazán. La luz en la batalla (Barcelona: Lumen, 2007), e Inés Alberdi, Emilia Pardo Bazán (Madrid: EILA Editores, 2013).

${ }^{3}$ José Luis Varela, «E. Pardo Bazán: epistolario a Giner de los Ríos», Boletín de la Real Academia de la Historia CXCVIII, cuadernos II y III (2001): 327-390 y 439-506; Ermitas Penas, "Giner de los Ríos en la formación de Emilia Pardo Bazán: a propósito de un epistolario», La Tribuna. Cadernos de Estudos da Casa Museo Emilia Pardo Bazán 2 (2004): 103-129.
} 
caso, la suya fue una formación de carácter básicamente autodidáctico, lo que no le impedirá convertirse en una de las escritoras más importantes de la España de la Restauración. ${ }^{4}$

En su obra se aprecia una preocupación persistente por los problemas educativos, plasmada, a nivel teórico, en textos como Los Pedagogos del Renacimiento (Erasmo, Rabelais y Montaigne) ${ }^{5}$ - conferencia pronunciada en el Museo de Instrucción Primaria-, y especialmente en sus múltiples escritos sobre las mujeres y su educación, ${ }^{6}$ problemática que también está muy presente en varias de sus obras literarias. ${ }^{7}$ La primera parte de nuestro trabajo consistirá precisamente en el análisis de la ponencia por ella presentada en el Congreso Pedagógico Hispano-Portugués-Americano (1892) acerca de la educación femenina.

En su trayectoria vital también se registra una actividad estrechamente relacionada con el mundo de la educación y la divulgación cultural, que tiene una de sus principales concreciones en las numerosas conferencias pronunciadas en escenarios muy diversos, algunas de ellas de temática pedagógica; el desempeño de la cátedra de Literatura Contemporánea de Europa y América de la Escuela de Estudios Superiores del Ateneo de Madrid (1896), siendo la primera señora merecedora de tal distinción; la edición de la Biblioteca de la Mujer, que puso al alcance de las españolas y los españoles algunas de las obras más importantes en materia de feminismo; la participación en iniciativas orientadas a la promoción de la formación y el trabajo de las mujeres, como es el caso del Taller de encaje creado en Madrid en 1915 por la condesa de San Rafael; su designación para formar parte del Consejo de Instrucción pública (1910), inaugurando así el acceso de las mujeres al principal órgano consultivo del Estado en materia educativa; y su nombramiento

\footnotetext{
${ }^{4}$ Los principales datos que poseemos sobre su formación proceden de sus Apuntes autobiográficos, que prologaron la primera edición de Los pazos de Ulloa (1886).

${ }^{5}$ Madrid: Fortanet, 1889.

${ }^{6}$ Algunos de estos textos pueden leerse en Emilia Pardo Bazán, La mujer española y otros escritos (Madrid: Cátedra, 1999), ed. Guadalupe Gómez-Ferrer.

${ }^{7}$ Teresa A. Cook, «Emilia Pardo Bazán y la educación como elemento primordial en la liberación de la mujer», Hispania 60, no. 2 (1977): 259-265; Marina Mayoral, «Estudo introdutorio» a Emilia Pardo Bazán, La educación del hombre y de la mujer. La dama joven. Memorias de un solterón (Santiago de Compostela: Sotelo Blanco Edicións, 2006), 11-80.
} 
como catedrática de la Universidad Central de Madrid (1916). ${ }^{8}$ Sobre este último aspecto versará la segunda parte de este artículo.

\section{EL CONGRESO PEDAGÓGICO DE 1892 Y LA EDUCACIÓN DE LAS MUJERES}

En octubre de 1892 se celebró en Madrid el Congreso Pedagógico Hispano-Portugués-Americano, enmarcado en los actos organizados para conmemorar los cuatrocientos años de la llegada de Cristóbal Colón a América. Una de sus secciones, la quinta, estuvo dedicada a la enseñanza de la mujer — «Concepto y límites de la educación de la mujer y de la aptitud profesional de esta»-, e incluía los siguientes temas: relaciones y diferencias entre la educación de la mujer y del hombre, organización de un sistema de educación femenina, aptitud de la mujer para la enseñanza y para el ejercicio de otras profesiones y educación física de la mujer. ${ }^{9}$

La inauguración tuvo lugar el 13 de octubre en el auditorio de la Universidad Central, con presencia del ministro de Fomento, y la clausura el 27 del mismo mes en el salón del Ateneo, prolongándose las sesiones bastante más de lo previsto por los organizadores. Se inscribieron 2.475 personas -130 procedentes del extranjero—, aunque el número de las que participaron fue notablemente inferior. Predominaba el profesorado de los diferentes niveles del sistema educativo, pero también tuvieron una presencia considerable los inspectores, los cargos superiores de la

\footnotetext{
${ }^{8}$ Cfr. Ángeles Ezama Gil, «La vocación pedagógica de Emilia Pardo Bazán», Moenia 18 (2012): 417-437.

${ }^{9}$ La bibliografía sobre este Congreso en general, y en particular sobre el tratamiento que en él mereció la educación de las mujeres, es relativamente abundante. Citaremos, sin afán de exhaustividad, los trabajos de Luis Batanaz Palomares, La educación española en la crisis de fin de siglo (Los Congresos pedagógicos del siglo XIX) (Córdoba: Diputación Provincial de Córdoba, 1982); Rosa M. ${ }^{a}$ Capel Martínez, «La apertura del horizonte cultural femenino: Fernando de Castro y los Congresos pedagógicos del siglo XIX», en Mujer y Sociedad en España (1700-1975), ed. M. ${ }^{a}$ Ángeles Durán y Rosa M. ${ }^{a}$ Capel (Madrid: Ministerio de Cultura, 1982), 109-145; Consuelo Flecha García, «Lo que piensan las mujeres acerca de su educación», Historia de la Educación. Revista Interuniversitaria 26 (2007): 395-435; Milagros Fernández Poza, «El debate educativo de finales del ochocientos y el Congreso Pedagógico Hispano-Portugués-Americano», Cuadernos de Historia Contemporánea, vol. extraordinario (2007): 71-82; Raquel Vázquez Ramil, Mujeres y educación en la España contemporánea. La Institución Libre de Enseñanza y la Residencia de Señoritas de Madrid (Madrid: Akal, 2012), 58-64; y Narciso de Gabriel, «A educación das mulleres no século xix: exclusión, dependencia e autonomía», Sarmiento. Anuario Galego de Historia da Educación 17 (2013): 7-35.
} 
administración pública, los periodistas, los escritores, los políticos o los representantes de asociaciones y corporaciones de diversa índole. ${ }^{10}$

Emilia Pardo Bazán tuvo un protagonismo particularmente importante en este Congreso. El día 16 leyó su ponencia sobre «Relaciones y diferencias entre la educación de la mujer y del hombre», el 17 presentó las conclusiones y el 19 hizo un resumen de las ponencias y memorias de la sección quinta. ${ }^{11}$ Sus ideas tuvieron además la virtud de polarizar buena parte de los debates, algunos de ellos ciertamente apasionados.

Después de pedir tolerancia al auditorio para las ideas que pudiesen resultar «desusadas y peregrinas», ${ }^{12}$ comenzó afirmando que las diferencias educativas entre uno y otro sexo superaban con mucho a las semejanzas. Advertía, no obstante, que se caminaba hacia una progresiva igualación, tal como ya estaba empezando a suceder en las naciones más cultas y avanzadas. Pero de momento, y desde luego en España, las relaciones eran pocas y superficiales, mientras que las diferencias eran muchas y profundas.

Su exposición se asienta en una concepción amplia de la educación, que incluye diversas dimensiones (física, moral, intelectual, religiosa, social, técnica, estética y cívica), abarca los procesos formativos de carácter formal e informal y se extiende largo de todo el ciclo vital. Pues bien, el principio sexual marca importantes diferencias en todas esas dimensiones. Las oposiciones resultaban especialmente acusadas en la educación moral — critica la «moral doble, monstruoso Jano que por un lado ríe con risa de sátiro y por otro se contrae con hipócrita mueca» (NTC, 3435)_, la intelectual — basada en el supuesto de la «inferioridad intelectual congénita de todo el sexo femenino»(NTC, 39-40)—, la estética y la cívica. La educación religiosa, por el contrario, era considerada algo más

\footnotetext{
${ }^{10}$ Rafael Altamira, «El movimiento pedagógico en España», La España Moderna 48 (1892): 149-151.

${ }^{11}$ Otras ponentes fueron Concepción Arenal, que no pudo asistir, pero cuyo texto fue objeto de lectura y discusión (me he ocupado de él en «A educación das mulleres no século xix: exclusión, dependencia e autonomía»), o Bertha Wilhelmi, que ha merecido la atención de Pilar Ballarín Domingo: «Bertha Wilhelmi y su defensa de la aptitud de la mujer para todas las profesiones», Arenal. Revista de Historia de las Mujeres 5, no. 1 (1998): 191-217.

${ }^{12}$ Emilia Pardo Bazán, «La educación del hombre y de la mujer. Sus relaciones y diferencias», Nuevo Teatro Crítico 22 (1892): 15. En este mismo número de la revista se publicaron las «Conclusiones de la Memoria» (60-66) y el «Resumen de las ponencias y memorias de la Sección V» (67-82). En adelante citaremos estas tres intervenciones en el cuerpo del texto como NTC, especificando únicamente el número de las páginas.
} 
equitativa, ${ }^{13}$ al menos a nivel doctrinal, y por más que el cristianismo discriminase a las mujeres y predicase su sumisión a los hombres. ${ }^{14}$

Pero lo que subraya más que nada es «el sentido diametralmente opuesto de los principios en que ambas educaciones se fundan» (NTC, 19). La del hombre se presupone que contribuirá a su progresivo perfeccionamiento, mientras que la de la mujer se piensa que conducirá a su perdición. Este «error» nace a su vez de otro:

el error de afirmar que el papel que a la mujer corresponde en las funciones reproductivas de la especie, determina y limita las restantes funciones de su actividad humana, quitando a su destino toda significación individual, y no dejándole sino la que puede tener relativamente al destino del varón. Es decir, que el eje de la vida femenina para los que así piensan (y son innumerables, cumple a mi lealtad reconocerlo), no es la dignidad y felicidad propia, sino la ajena, la del esposo e hijos, y si no hay hijos ni esposo, la del padre o del hermano, y cuando estos faltaren, la de la entidad abstracta género masculino (NTC, 20-21).

Tal era la concepción de la mujer sustentada por Jean-Jacques Rousseau en Emilio o De la educación, cuyo último capítulo traza el perfil de la educación que convenía a Sofía, la compañera de Emilio. El pensador ginebrino sostenía que agradar a los hombres, hacerse amar y honrar por ellos, educarlos en su niñez y cuidarlos en su vejez, prestarles consejo y consuelo y hacerles la vida fácil y agradable, «son las obligaciones de

\footnotetext{
${ }^{13}$ Emilia Pardo Bazán se excusaba de «rozar siquiera la delicada cuestión de si debe darse en la escuela y el aula o solo dentro de la familia» (NTC, 35). Otro congresista, Manuel González, después de felicitar a la escritora gallega por su «erudita y magistral Memoria», propuso que se discutiese sobre el «carácter» que se debería imprimir a la enseñanza religiosa en los colegios públicos, aunque la propuesta no tuvo éxito. En su opinión, tal enseñanza habría de tener una orientación «fraternal y tolerante», huyendo del sectarismo. Congreso Pedagógico Hispano-Portugués-Americano (Madrid: Librería de la Viuda de Hernando y C. $\left.{ }^{a}, 1894\right), 116$; en adelante citaremos en el cuerpo del texto como CPHPA, registrando solamente la página a la que corresponde la cita.

${ }^{14}$ Sobre la situación educativa de las mujeres en la España de la época puede leerse la síntesis realizada por Pilar Ballarín, La educación de las mujeres en la España contemporánea (siglos XIX y XX) (Barcelona: Síntesis, 2001). El papel desempeñado por la Institución Libre de Enseñanza en este ámbito ha sido analizado en diversas obras, entre ellas la publicada por Ramón Emilio Mandado Gutiérrez, Juana Sánchez-Gey Venegas y Benito Madariaga de la Campa: La Institución Libre de Enseñanza y la Asociación para la Enseñanza de la Mujer. Bosquejo histórico de la educación española del siglo XIX (Santander: UIMP, 2011). Historia de la Educación. Revista Interuniversitaria, dedicó a esta temática su número 26 (2007), coordinado por Consuelo Flecha.
} 
las mujeres en todos los tiempos, y esto es lo que desde su niñez se les debe enseñar». ${ }^{15}$ Debían recibir lo que podemos denominar una educación para la dependencia, esto es, una educación cuyo referente no son ellas mismas, sino el género masculino en cualquiera de sus versiones: padres, esposos e hijos. Contra este modelo educativo se rebela de forma explícita, abierta y valiente doña Emilia, como ya se habían rebelado antes otras mujeres. ${ }^{16}$ Apelando a James Mill, reclamaba que la educación debía procurar, en primer término, la propia felicidad.

La escritora gallega había defendido estas ideas antes de celebrarse el Congreso Pedagógico ${ }^{17}$ y las seguirá defendiendo después, ${ }^{18}$ pero será ahora cuando lo haga de una forma más sistemática. También las defendía, aunque con menor énfasis, Concepción Arenal, que presentó en este mismo encuentro pedagógico una memoria en la que abordaba todas las cuestiones incluidas en la sección quinta. En ella sostenía que «lo primero que necesita la mujer es afirmar su personalidad, independiente de su estado». ${ }^{19}$

La reivindicación de la autonomía femenina impedía a doña Emilia aceptar que se apelase a la maternidad para legitimar la educación de las mujeres. Como se venía repitiendo con insistencia cansina, esta se justificaba, en todo caso, en virtud de su condición de futuras madres educadoras. La condición maternal también servía para defender el acceso de las mujeres a la profesión docente en los niveles infantil y primario, considerados como una especie de extensión de las tareas maternales. Esta forma de argumentar era utilizada por quienes querían mantener a las mujeres en un estatus de sumisión y dependencia, para el que debían ser

\footnotetext{
${ }_{15}^{15}$ Jean-Jacques Rousseau, Emilio o De la Educación (Barcelona: Fontanella, 1973, 1. a ed. 1762), 249250. Para un análisis sobre el pensamiento de Rousseau acerca de la educación de las mujeres, véase Rosa Cobo, Fundamentos del patriarcado moderno. Jean Jacques Rousseau (Madrid: Cátedra, 1995).

${ }^{16}$ Mary Wollstonecraft, Vindicación de los Derechos de la Mujer (Madrid: Cátedra, 1994, 1. ${ }^{\text {a }}$ ed. 1792).

${ }^{17}$ El 15 de marzo de 1892 publicó en su revista Nuevo Teatro Crítico (escrita íntegramente por ella) una reseña del discurso pronunciado en la Academia de Medicina por el Marqués del Busto. Su autor incurría en el error común de atribuir a la mujer un «destino de mera relación», pues no la consideraba «en sí, ni por sí, ni para sí, sino en los otros, por los otros y para los otros» («Una opinión sobre la mujer» 15 (1892): 77).

${ }^{18}$ Al reseñar La educación de la mujer (1904), libro del argentino Carlos Octavio Bunge, aplaudía algunas de sus ideas, pero se distanciaba radicalmente de él cuando afirmaba que la educación «debe mantener en la masa femenina el tipo medio de la mujer mera esposa y madre» ( «La vida contemporánea», La Ilustración Artística, 1200 (1904): 842).

${ }^{19}$ Concepción Arenal, «Educación de la mujer», Boletín de la Institución Libre de Enseñanza 377 (1892): 307.
} 
debidamente socializadas, pero también recurrían a ella los partidarios de una cierta emancipación femenina. Para conseguirla era imprescindible el acceso a la educación y a un trabajo asalariado, y el argumento de la maternidad, incluso cargado de connotaciones patriarcales, podía contribuir tanto a lo uno como a lo otro. Doña Emilia lo sabía, como también sabía que al pronunciarse en estos términos perdía aliados, pero entendía que en lo fundamental no se podía transigir. La mujer debía ser instruida «en primer término para sí»:

Aunque no es costumbre en buena estrategia rechazar aliados, yo he de desprenderme de unos que considero funestos: los que encarecen la necesidad de educar intelectualmente a la mujer, para que pueda transmitir la enseñanza a sus hijos. Rechazo esta alianza, porque, insisto en ello, considero altamente depresivo para la dignidad humana, representada por la mujer tanto como por el hombre, el concepto del destino relativo, subordinado al ajeno (NTC, 44-45).

Al presentar las conclusiones de su ponencia, se felicita por «la unanimidad de miras y voluntades» observada en la sección quinta. Reconocía que inicialmente desconfiaba de la receptividad que encontrarían sus «ideas radicales» en el Congreso, pero pudo "comprobar que casi todas las voces que aquí se han alzado son voces de libertad y vida», y reclamaban para la mujer derechos educativos «equivalentes» a los del hombre (NTC, 60-61). Las conclusiones por ella presentadas se limitaron a dos, la primera de las cuales tenía un carácter teórico:

Aspiro, señores, a que reconozcáis que la mujer tiene destino propio; que sus primeros deberes naturales son para consigo misma, no relativos y dependientes de la entidad moral de la familia que en su día podrá constituir o no constituir; que su felicidad y dignidad personal tienen que ser el fin esencial de su cultura, y que por consecuencia de este modo de ser de la mujer, está investida del mismo derecho a la educación que el hombre, entendiéndose la palabra educación en el sentido más amplio de cuantos puedan atribuírsele (NTC, 62).

Lo que se pedía a los congresistas era que impugnasen el carácter «relativo» o dependiente que impregnaba los discursos pedagógicos, 
morales, sociales y políticos sobre la educación femenina, o lo que es igual, que se enterrase definitivamente a Sofía. Unos discursos que eran ampliamente hegemónicos y de los que incluso participaban muchas personas que se erigían en defensoras de la causa femenina. Es en este escenario donde debemos situar la propuesta de doña Emilia, que tenía un carácter abiertamente rupturista. Más no se les podía proponer, en el plano teórico, a los congresistas.

La segunda conclusión, de carácter práctico, era una consecuencia de la anterior. Se solicitaba a todas las naciones representadas en el Congreso, y particularmente a España, que concediesen a las mujeres el derecho de acceder a la enseñanza sin ningún tipo de restricciones y en concurrencia con los hombres, y que se les permitiese, por consiguiente, el desempeño de los empleos y cargos que estuviesen en sintonía con los títulos conseguidos:

Hoy por hoy, aquí se admite a la mujer libremente a la segunda enseñanza; en la superior solo ingresa por una especie de concesión graciosa y sujeta a condiciones que dependen de la buena voluntad de los Sres. Rectores y Profesores; y después de haber sido recibidas así, como por lástima o por excepción que impone una singularidad fenomenal, rara vez y en contadísimas profesiones se les permite ejercer lo que aprendieron y aprovecharlo para asegurar la independencia de su vida, o para ejercitar el santo derecho de seguir la vocación propia, la voz misteriosa que nos llama a seguir nuestro camino y emplear nuestras facultades según quiso Aquel que a su voluntad las distribuye (NTC, 63).

El acceso al sistema educativo y al trabajo remunerado eran dos reivindicaciones centrales del incipiente feminismo español. Se había conseguido una progresiva incorporación de las niñas a las escuelas primarias; si en 1850 representaban el 29,78\% de la matrícula en el conjunto de España, en 1885 ascendían al 44,53\%. ${ }^{20}$ Pero su presencia era insignificante en la enseñanza secundaria y superior. En octubre de 1892, cuando se celebró el Congreso Pedagógico, había siete alumnas en las universi-

\footnotetext{
${ }^{20}$ Narciso de Gabriel, Leer, escribir y contar. Escolarización popular y sociedad en Galicia (1875-1900) (Sada-A Coruña, Ediciós do Castro, 1990), 254.
} 
dades españolas. ${ }^{21}$ En lo que respecta al trabajo, lo que estaba en cuestión era, más que nada, la posibilidad de ejercer profesiones liberales como la medicina o la abogacía. ${ }^{22}$

En su tercera intervención en el Congreso, dedicada a presentar un resumen de las memorias y ponencias de la sección quinta, Emilia Pardo Bazán insiste de nuevo en la unanimidad que había presidido los debates sobre la enseñanza de la mujer. La «inmensa mayoría» de los que reflexionan sobre ella "ven el problema de un modo casi idéntico». Parecía como si entre las personas que habían intervenido sobre este tema existiese

el misterioso nexo común de un ideal que flota en la atmósfera de nuestro siglo y que, impregnando a la vez nuestras almas, nos ha inspirado palabras tan afines y hasta frases enteras tan idénticas, que si no supiésemos cuán imposible es el caso, diríase que nos habíamos plagiado los unos a los otros (NTC, 68-69).

Ahora bien, la unanimidad de la que se presumía se limitaba, en todo caso, y con matices, algunos importantes, a los ponentes. Entre el resto de los congresistas las discrepancias no eran menores y los debates fueron intensos y en ocasiones apasionados, viéndose obligados a solicitar calma quienes presidían las sesiones.

Francisco Romero Blanco, rector de la Universidad de Santiago de Compostela, pidió la palabra para manifestar su conformidad con las conclusiones de la ponencia, siempre que se rectificasen «ligeramente, y una de ellas mucho", aunque en realidad las cuestionó todas abiertamente. En todo caso, la que necesitaba muchos cambios «es la que dice que lo primero y más fundamental en la mujer es su independencia del hombre» (CPHPA, 153). Lo que el rector no aceptaba - y tampoco otros muchos congresistas, seguramente la mayoría - era precisamente la base sobre la que Pardo Bazán pretendía asentar el nuevo modelo de educación femenina. Frente a una educación para la autonomía, el máximo responsa-

\footnotetext{
${ }^{21}$ Consuelo Flecha García, Las primeras universitarias en España (Madrid: Narcea, 1996), 138.

${ }^{22}$ Nuestra protagonista estaba especialmente preocupada por ensanchar el estrecho horizonte profesional de las mujeres. Algunas de sus reflexiones sobre esta temática están recogidas en La mujer española y otros escritos. Sobre el acceso de las mujeres al sistema educativo y a las profesiones, véase Pilar Ballarín Domingo, «Entre ocupar y habitar. Una revisión historiográfica sobre Mujeres y Universidad en España», Arenal. Revista de Historia de las Mujeres 17, no. 2 (2010): 223-254.
} 
ble de la universidad gallega seguía apostando por una educación para la dependencia. Crescencia Alcañiz, maestra de Guadalajara y ponente del tema «Aptitud de la mujer para la enseñanza», aplaudió, por el contrario, la elocuencia con la que doña Emilia defendió que la mujer «viva vida individual, por sí, para la sociedad y para sí»(CPHPA, 125).

Fueron varias las voces que insistieron en que la ilustración de las mujeres debía encaminarse a la formación de buenas esposas y madres. Así lo afirmaba el médico Francisco Calatraveño, según el cual lo que debía procurarse era formar a «la compañera del hombre» y a la «maestra de sus hijos»(CPHPA, 162). En la misma linea se pronunciaba otra congresista, maestra de profesión y apellidada Rubio, que se oponía a todo lo que no fuese aleccionar a las mujeres para «cumplir sus deberes de hija, esposa y madre» (CPHPA, 169). Carmen Rojo, ponente del tema segundo y directora de la Escuela Normal de Maestras de Madrid, aun reconociendo la importancia de la maternidad, añadía sin embargo que la mujer no es solo madre, "sino individuo de la especie humana, con voluntad y conciencia, con personalidad y valor propio» (CPHPA, 125).

El acceso de las mujeres a la enseñanza secundaria y superior y al ejercicio de las profesiones liberales también encontró fuertes resistencias. Algunos se oponían por dudar de sus capacidades intelectuales, en todo caso inferiores a las de los hombres; otros invocaban su singularidad biológica, que las convertía en enfermas crónicas, o sus deberes maternales, que necesariamente desatenderían si se convertían en abogadas o médicas. Quienes así argumentaban no se oponían sin embargo a las prolongadas y penosas jornadas de trabajo a que estaban sometidas las proletarias: "Esas sí que tienen que dejar en el mayor abandono a los hijos y al hogar», argumentaba Agustín Sardá, profesor de la Escuela Normal de Madrid. Y continuaba: «Si un obrero hubiese escuchado estas discusiones y los argumentos limitados a las mujeres de clase media, ¡cómo se habría dolido de tanta estrechez de miras, y cómo hubiera estigmatizado los egoísmos de la burguesía!» (CPHPA, 168).

A mayores, el acceso de las jóvenes a institutos y universidades significaba que se verían obligadas a convivir con los chicos, y todavía eran muchos los que rechazaban la enseñanza mixta. Pardo Bazán trataba de vencer las resistencias con diversos argumentos, e incluso traía a colación el ejemplo de su propia hija, que asistía, sin ningún problema, al ins- 
tituto Cardenal Cisneros de Madrid. Así lo hizo notar en su intervención María Amalia Goyri, maestra e institutriz:

Encuentro que la Sra. Pardo tiene en su ventaja el sustentar ideas que practica; pues si es verdad que ha llegado al puesto que ocupa sin ser doctora, no por eso ha dejado de tener que luchar, y eso que posee condiciones que pocas mujeres podrán reunir, pues además de excepcionales dotes de talento y laboriosidad, tiene medios materiales que la ayudan a abrirse camino. Esta señora, que como ha demostrado no teme la lucha, expone también a ella a uno de sus seres queridos, a su hija (CPHPA, 166).

La principal opositora a las ideas de Pardo Bazán fue Ana María Solo de Zaldívar, profesora de la escuela aneja a la Normal de Maestras de Madrid, que intervino repetidas veces para impugnarlas. Se oponía a la educación mixta en todos los niveles del sistema educativo, sin ningún tipo de matiz: «Me opongo a que la niña asista a la Escuela confundida con el niño; la joven en el Instituto con el joven; la mujer en la Universidad con el hombre» (CPHPA, 136). Esta confusión de sexos podía provocar que la mujer perdiese sus cualidades intrínsecas (CPHPA,154) y se convirtiese en un marimacho (CPHPA, 163). Bajando un tanto el nivel del debate, reconocía su interés por saber cuáles eran los «antecedentes» de las «Doctoras» que algunos invocaban como ejemplos «en lo que se refiere a su vida moral y al estado de sus casas» (CPHPA, 160). Pero a pesar de oponerse a las ideas de la ponente, y de pedir expresamente que se votase en contra de ellas, reconocía sus «aptitudes especiales», y añadía que su trayectoria constituía la mejor demostración de que la mujer no estaba discriminada: «Del mismo modo que la Sra. Pardo Bazán ha llegado a ser una literata eminente española, toda mujer que posea condiciones especiales para una rama del saber humano ocupará su puesto, no lo dudo, sin abrir la puerta a todas las medianías y nulidades para fomentar la vanidad femenina y el celibato» (CPHPA, 136). ${ }^{23} \mathrm{Y}$ le gustaría poder discutir con ella, pero directamente y sin papeles de por medio: «invito a la Sra. Pardo Bazán a que conteste de palabra, no por escrito, a estas objeciones, puesto que, consecuente en mis ideales, no quiero discutir

\footnotetext{
${ }^{23}$ Agustín Sardá subrayaba, por el contrario, la persistencia de las discriminaciones, pues la escritora gallega, cuyos méritos literarios nadie cuestionaba, «si pretendiese entrar en la Academia de la Lengua, de seguro que encontraría las puertas cerradas» (CPHPA, 168).
} 
con el señor Torres Campos, por ser más aceptable para mí la lucha con señoras»(CPHPA, 136). La interpelada no recogió el guante.

Excluidas las siete conclusiones de carácter general, se sometieron a la consideración de los congresistas 50, correspondientes a las cinco secciones del Congreso: enseñanza primaria (14), secundaria (7), técnica (11), superior (6) y de la mujer (12). Recibieron en conjunto 20.452 votos afirmativos, 3.930 negativos y 8.018 abstenciones de los 648 congresistas que participaron en la votación (CPHPA, 241-246). Sumando las cuatro primeras secciones, los votos positivos representaban, en números redondos, el $65 \%$, los negativos el $7 \%$ y las abstenciones el $28 \%$, mientras que en la sección quinta los votos a favor fueron ocho puntos inferiores (57\%), los negativos se multiplicaron por cuatro (28\%) y las abstenciones se redujeron casi a la mitad (15\%), porque, como es sabido, sobre la cuestión femenina casi todo el mundo se sentía capacitado para pontificar.

De las doce conclusiones de la sección quinta, tres suscitaron más rechazos que adhesiones. La que tuvo más votos en contra fue la que preguntaba si las escuelas primarias mixtas debían encomendarse exclusivamente a las maestras, a quienes el gobierno había acordado recientemente dar prioridad para este tipo de escuelas, con el propósito de ampliar así las posibilidades laborales de las mujeres. También merecieron más noes que síes las preguntas de si debía facilitárseles la cultura necesaria para el ejercicio de todo tipo de profesiones y el acceso, en concurrencia con los hombres, a los centros educativos de enseñanza secundaria, especial y superior. ${ }^{24}$ Las cuestiones referidas a si la educación femenina debía tener igual «dirección e intensidad» que la masculina y si

\footnotetext{
${ }^{24}$ Se aprobó, con el 70\% de votos a favor, que se creasen centros específicos de esta clase para las mujeres. Esta propuesta estaba en sintonía con la defendida por la ponente Carmen Rojo (CPHPA, 108-109), de la que discrepaba Pardo Bazán (NTC, 76-77). En carta remitida a El Liberal (27 de octubre de 1892) Carmen Rojo se desmarcaba de las posiciones sustentadas por otros congresistas: «En mi Memoria y en mis conclusiones — dice la señorita Rojo- he sostenido, y sostengo, que la educación de la mujer es deficiente, que es necesario darle otra dirección para que pueda bastarse a sí misma y subvenir a sus necesidades por medio del trabajo; pero que jamás se la desvíe de su condición ni de las ocupaciones y virtudes que le son propias. Que para conseguir esto es necesario reformar la Escuela primaria para las clases populares, crear Escuelas superiores como medios de educación complementaria para la joven y crear cursos epeciales en las Normales de Maestras para la enseñanza superior de la mujer, aunque no se dedique a una carrera especial.

Soy opuesta, y escrito está en mi Memoria, a la escuela mixta que defendió el señor Sardá; a la igualdad de derechos y profesiones entre el hombre y la mujer que sostuvo la señora Pardo Bazán; a que la mujer siga los estudios en las Universidades o Institutos con los varones, como quiere la mayoría de las oradoras del Congreso, y mucho menos que la mujer sea marino o marina, como pretende la señorita La Rigada».
} 
debía ampliarse el número de escuelas primarias mixtas fueron aprobadas, aunque recibieron un porcentaje de votos favorables inferior al 50\%.

Como se puede apreciar, la conclusión práctica propuesta por Emilia Pardo Bazán resultó derrotada: los congresistas rechazaron el libre acceso de las mujeres a las profesiones, restringiendo sus opciones a las que estaban en armonía con las aptitudes específicas que se les atribuían, y también se opusieron a la posibilidad de que compartiesen con los hombres el currículo, el espacio y el tiempo escolar. Su conclusión teórica ni siquiera fue sometida a votación. Sus compañeros y compañeras seguramente la convencieron, en la reunión celebrada para elaborar las conclusiones, de que no resultaría oportuno reivindicar la soberanía educativa femenina, y de que debía apoyar la siguiente propuesta: «El Congreso reconoce y declara que la mujer tiene los mismos derechos que el hombre para desenvolver y cultivar, en bien propio y de la especie, todas sus facultades, así físicas como intelectuales» (CPHPA, 244). Se reconocía así a la mujer el derecho a cultivarse en beneficio de la especie, pero también de sí misma. La propuesta posiblemente le supo a muy poco a doña Emilia. Aun así, solo consiguió el apoyo del 70\% de los congresistas.

En una entrevista realizada en 1919, María Encarnación de La Rigada atribuía la derrota de las propuestas más radicales de la autora de Los Pazos de Ulloa a las intervenciones de Ana María Solo de Zaldívar, que había conseguido cautivar al auditorio con sus vehementes intervenciones. ${ }^{25}$ Ahora bien, sin pretender restar méritos a la elocuencia de la maestra andaluza, lo cierto es que la razón de fondo del mencionado rechazo obedecía a la mentalidad dominante en la sociedad española acerca de las mujeres y de su educación. Rafael Altamira no se llamaba a engaños

\footnotetext{
25 «Practicaba la maestra andaluza [Solo de Zaldívar] un feminismo que pasa en España por atrevido. Emancipada de su familia, vivía en casa de huéspedes e iba sola a todas partes, acompañada únicamente de su dignidad. Sin embargo, en el curso de la discusión se pronunció, con una elocuencia que sus más íntimas amigas no sospechábamos, ni mucho menos, que la pusiera al servicio de lo que era opuesto a sus costumbres, en contra de las aspiraciones feministas defendidas en el discurso de Emilia Pardo Bazán. Tales mañas se dio mi amiga, que cautivó al auditorio con su gracejo andaluz» (José G. García, «Intervius con la directora de la Escuela Normal Central de Maestras», El Día, 17 de noviembre de 1919). La prensa se hizo eco en repetidas ocasiones de sus intervenciones. Sirva como ejemplo El Liberal. Diario Democrático de Menorca (25 de octubre de 1892): «No se habla de otra cosa en Madrid. La Srta. Zaldívar, maestra, se ha revelado en el Congreso pedagógico como un terrible parlamentario, como "un Romero Robledo con faldas" ». Cuando se oponía a las propuestas más innovadoras y radicales, «se llevaba al público de calle y resonaban aplausos estrepitosos en el público y bravos entusiastas entre los congresistas».
} 
y hacía notar que si bien "pareció al fin que el Congreso cedía bastante en favor de la mujer», aceptando algunas propuestas, lo cierto era que esa relativa «victoria formal, satisfactoria en una primera campaña, no asegura, por desgracia, de la inclinación interna y convencida del público que, por otra parte, sería locura pretender conseguir de golpe, contra la inmensa fuerza de la tradición y la rutina». ${ }^{26}$

Por lo demás, desde determinadas instancias se intentó deslegitimar el Congreso, incluso antes de su comienzo. La Escuela Moderna lamentaba la campaña organizada por dos o tres periódicos profesionales con el propósito de evitar que el magisterio de primera enseñanza acudiese a esta asamblea, al tiempo que se felicitaba del escaso éxito cosechado por los boicoteadores. ${ }^{27} \mathrm{~A}$ esta campaña se unirá y dará cobertura el catolicismo militante. La Unión Católica publicó un extenso artículo denunciando que el encuentro pedagógico proyectado estaba «promovido y dirigido» por la Institución Libre de Enseñanza, que se había dotado de los mecanismos necesarios para controlar el curso de los debates. El presidente (Rafael María de Labra), los vicepresidentes (Valentín Morán y Agustín Sardá) y los secretarios (Rafael Salillas y Manuel Díaz de Ocaña) de la comisión organizadora representaban únicamente a la «diminuta agrupación político filosófico religioso pedagógica» que tenía su sede en la calle del Obelisco, así como a dos de sus «sucursales», el Fomento de las Artes y la Asociación para la Enseñanza de la Mujer. Las conclusiones tendrían, por tanto, un carácter sectario, pues reflejarían el sentir del krausismo, una «escuela» o «partido» alejado de Dios, que ya había manifestado su incapacidad para dirigir los destinos educativos del país durante la Revolución de 1868. De todo ello se quería advertir a quienes no compartían los ideales de la «Academia krausista-froebeliana», para que no contribuyesen a legitimar con su presencia tal acontecimiento. ${ }^{28}$

\footnotetext{
${ }^{26}$ Altamira, «El movimiento pedagógico en España», 154.

${ }^{27}$ La Escuela Moderna 16 (1892): 71-72. El número de maestros y maestras inscritos ascendió finalmente a 688 de la enseñanza pública y 288 de la privada (Altamira, «El movimiento pedagógico en España», 150).

${ }^{28}$ F. G. Ayuso, «La Instrucción Pública y el Congreso Pedagógico Hispano-Portugués-Americano», La Unión Católica 5 y 14 de septiembre de 1892. El 7 de octubre, una semana antes de inaugurarse el Congreso, este mismo diario publicaba un artículo de Miguel Amat sobre «Las escuelas laicas» en el que también se aludía a la ILE: «Pronto vamos a ver en España, figurando en el Congreso pedagógico, a los partidarios de la educación libre, anticatólica y antiespañola. Sepamos antes que llegue el caso, el campo en que cada cual combate, y expongamos lealmente las razones en que cada cual se apoya».
} 
El 22 de octubre, cuando todavía no habían concluido los debates, el escritor Leopoldo Pedreira publicó un artículo para unirse a las protestas que el día anterior había intentado formular en la asamblea general del Congreso, en nombre propio y de La Ilustración Nacional, el también escritor Baldomero Lois. No había podido hacerlo, al prohibírselo Labra, de modo que Pedreira se sentía obligado a convertirse en su portavoz. La protesta estaba motivada ahora por el temor de que fuesen aprobadas «las conclusiones verdaderamente perniciosas y absurdas que el señor Labra y la señora Pardo Bazán imponen al Congreso». ${ }^{29}$ La suma de sus esfuerzos había conseguido convertir la educación de la mujer en el principal tema, a pesar de tratarse de un asunto «más antropológico que pedagógico»; orillar otras cuestiones de indudable relieve, como la enseñanza técnica; y encauzar las discusiones en una dirección favorable a las ideas de la escritora gallega, que, por cierto, estaba ansiosa de «penetrar en una Academia masculina» - y Pedreira seguramente no estaba menos ansioso de contarlo. Cuando los lectores de La Unión Católica leyesen estas palabras, seguramente ya estaría aprobada la memoria presentada por doña Emilia, «en virtud de la cual se declara a la mujer igual al hombre y se la capacita para todos los cargos masculinos, concediéndole iguales derechos, pero sin imponerla los mismos deberes». Estas ideas, además de ser "perfectamente anticristianas», constituyen «una monstruosidad ante la sociología, ante la moral, ante la economía, ante las ciencias naturales y ante los intereses del sentimiento y del arte». ${ }^{30}$ Nada menos.

Así pues, la formulación de las conclusiones y su votación —particularmente las defendidas por Emilia Pardo Bazán, «reducida hoy a satélite de los de la Institución libre de enseñanza»—, ${ }^{31}$ constituían ahora el centro de las discusiones. El reglamento establecía que la votación se haría

\footnotetext{
${ }^{29}$ Luis Vidart, amigo íntimo de doña Emilia, remitió una carta a El Liberal (23 de octubre de 1892) advirtiendo que Baldomero Lois hablaba en su propio nombre y no en el de La Ilustración Nacional, de cuya redacción formaban parte el propio Vidart y Alfonso Ordax y Avecilla. Ambos coincidían con la orientación de las ponencias redactadas por Concepción Arenal, Emilia Pardo Bazán y Bertha Wilhelmi de Dávila, y daban fe como congresistas de la imparcialidad de Rafael María de Labra como moderador de las sesiones.

${ }^{30}$ Leopoldo Pedreira, «Congreso Pedagógico. Protesta», La Unión Católica, 22 de octubre de 1892. Ese mismo día, El Siglo Futuro afirmaba que «una ilustre noveladora, que lo mismo entona himnos a San Francisco que escribe invocaciones», había defendido en el Congreso Pedagógico «la emancipación absoluta de la mujer».

31 «El fracaso de una maniobra», La Unión Católica, 28 de octubre de 1892.
} 
en la sesión de clausura, pero al haberse superado ampliamente los días previstos para la realización del Congreso, una buena parte de los congresistas ya habían regresado a sus lugares de origen. Atendiendo a esta circunstancia, así como a lo complejo que resultaría votar nominalmente todas y cada una de las conclusiones, se propuso a la asamblea general, y esta aceptó por unanimidad, que la votación se realizase mediante papeletas que se enviarían a los congresistas y que estos devolverían a la secretaría del Congreso.

Tal como se había acordado, el 26 de octubre se procedió a la lectura de las conclusiones, elaboradas por la Comisión de conclusiones y publicaciones. Su presidente, Pedro de Alcántara García, explicó que se habían redactado en colaboración con los ponentes de todas las secciones y atendiendo a las propuestas de estas y a los debates producidos en las asambleas generales. Varios congresistas cuestionaron sin embargo «la forma en que estaban redactadas las conclusiones» (CPHPA, 210). El libro de actas no pormenoriza las discrepancias, pero El Día hacía saber que se produjo «un regular alboroto durante la lectura, pidiendo la palabra al leerse las [conclusiones] de la enseñanza de la mujer, el Sr. Alba», y que el presidente, «en vista del escándalo que se producía a cada petición de palabra, dijo que debían los señores congresistas manifestarse dignos del respeto de propios y extraños y de la importancia y trascendencia del Congreso». ${ }^{32}$

El escándalo subió de tono en la sesión de clausura, celebrada al día siguiente. Cuando se iban a pronunciar los discursos de rigor, un congresista pidió la palabra para solicitar que se procediese a la votación inmediata de las conclusiones, obviando el acuerdo adoptado durante la sesión anterior. Ante la negativa del presidente, los reclamantes pretendían que constase en acta el contenido de un escrito firmado por unos cien congresistas denunciando que las conclusiones no reflejaban el espíritu del Congreso y anunciando que se abstendrían de votar, pues no querían contribuir a la legitimación de los acuerdos, ni siquiera con su voto en contra. ${ }^{33}$ Labra tampoco accedió a esta pretensión, por considerarla improcedente, haciendo saber a los discrepantes que podían trasladar su

${ }^{32}$ El Día, 27 de octubre de 1892.

${ }^{33}$ El Día, 28 de octubre de 1892. 
protesta a la opinión pública a través de los medios usuales. De momento, estos abandonaron el salón donde se celebraba el acto.

«Muy triste, muy doloroso espectáculo», plagado de «interrupciones, gritería, protestas, palabras gruesas», se podía leer en Las Dominicales del Libre Pensamiento; «alboroto de gritos, voces e imprecaciones», escribía La Época; se temió que el acto de clausura terminase como el rosario de la aurora, apostillaba El País; escándalo «morrocotudo y merecidísimo», aplaudía La Unión Católica, que añadía:

No deben quedar así las cosas. Los que tan valerosamente han peleado contra los manejos de los de la Institución libre de enseñanza, deben reunirse, deben concertarse, deben preparar un plan de batalla que acabe de una vez con esa institución, que es un baldón para la patria, plantel de charlatanes elocuentes, los que lo son, que se llaman liberales y luego obran como el Sr. Labra en la presidencia del Congreso Pedagógico. ${ }^{34}$

Las protestas continuaron una vez clausurado el Congreso. Un escrito que se decía firmado por más de 200 congresistas, la mayor parte maestros de primera enseñanza, encabezados por Eugenio Cemborain España, ${ }^{35}$ alertaba a los poderes públicos de la falta de legitimidad de unas conclusiones que todavía, y conviene subrayarlo, no habían sido aprobadas, y algunas de las cuales, precisamente las que más alarmaban a los protestantes, serían, como ya sabemos, rechazadas. Las autoridades no deberían prestar atención a los acuerdos alcanzados en una asamblea monopolizada y controlada de forma sectaria por personas ajenas al sentir del pueblo español en general y del magisterio en particular. Esto era especialmente cierto en lo relativo a la enseñanza de la mujer, que parecía ser la principal preocupación de los organizadores, y al parecer también de los abajo firmantes:

Entraba, sin duda alguna, en los planes de los organizadores del Congreso obtener, como nota dominante de las deliberaciones, como característica de su resultado, la totalidad de los votos a favor de una absurda y anticristiana emancipación de la mujer;

\footnotetext{
${ }^{34}$ Todos los textos corresponden a las ediciones del 28 de octubre de 1892.

${ }^{35}$ La Gaceta de Instrucción Pública afirmaba que la protesta estaba suscrita por Eugenio Cemborain, «Catedrático INTERINO de la Escuela Normal Central», y una docena de profesores de enseñanza primaria, «subrogándose representaciones ilusorias» (25 de noviembre de 1892).
} 
bien pronto la asamblea, a pesar del férreo círculo en que los estatutos la habían encerrado, manifestose claramente en contraria opinión; pero en este caso la mesa y la comisión de conclusiones, persistiendo en sus propósitos de incalificable absorción, encontraron el modo de prescindir de muchas proposiciones aprobadas por las secciones, eliminaron totalmente las presentadas por la directora de la Escuela Normal Central de Maestras, la ilustrada señorita doña Carmen Rojo, únicas que hubieran podido ser aceptadas, y presentaron, en fin, al Congreso, una serie de conclusiones que no reflejaban el espíritu de las secciones ni el de la asamblea en general. ${ }^{36}$

A este manifiesto se unió otro dirigido a los maestros de España, encabezado también por Eugenio Cemborain España y con un contenido similar, aunque en este caso se subrayaba la escasa consideración que merecía el magisterio a los teóricos de la ILE. Tampoco se olvidaban los firmantes de criticar el tratamiento que se había dado a la educación de las mujeres, a las que se pretendía sacar «del templo augusto del hogar doméstico» para llevarlas a «cátedras, oficinas y estrados». ${ }^{37}$

Así pues, la enseñanza de las mujeres estaba en el origen de buena parte de las críticas, que tenían como principal blanco a doña Emilia. Leopoldo Alas fue uno de los que la atacaron con más contundencia. Inicialmente su relación era cordial, y Clarín incluso escribió el prólogo a La cuestión palpitante (1883), pero con el tiempo fueron distanciándose, y el escritor asturiano será cada vez más mordazmente crítico con la escritora gallega. ${ }^{38}$ Tanto que según esta padecía "pardobazanfobia», y con motivo de su muerte se preguntaba en carta a Emilio Ferrari: «¿Quién nos desgarrará como aquel perro? Mire V. que yo pasé cuatro o seis años de mi vida sin que un solo instante dejasen de resonar en mis oídos los ladridos furiosos del can». ${ }^{39}$

\footnotetext{
${ }^{36}$ «Los maestros de primera enseñanza a los poderes públicos», El Imparcial, 4 de noviembre de 1892. 37 «A los maestros de primera enseñanza de España», La Unión Católica, 4 de noviembre de 1892. La pugna entre los organizadores del Congreso y sus detractores se prolongó durante algún tiempo, y así lo atestigua la prensa de la época, que publica artículos en los que unos y otros defienden sus posiciones, e informa de los los homenajes que cada sector tributa a sus líderes.

${ }^{38}$ Ermitas Penas, Clarín, crítico de Emilia Pardo Bazán (Santiago: Universidade de Santiago de Compostela, 2003).

${ }^{39}$ Acosta, Emilia Pardo Bazán, 409 y 448.
} 
Clarín entendía que en el Congreso no habían hablado quienes deberían haber hablado, como era el caso de don Francisco Giner de los Ríos, y hablaron más de lo debido «ciertos polígrafos y polígrafas». El interés se centró además en un tema, la enseñanza de la mujer, planteado de "forma radical y nada práctica», obviándose los verdaderos y perentorios problemas de la educación nacional. «De todo esto ha tenido mucha culpa doña Emilia Pardo Bazán, que va dando a sus naturales y legítimas aspiraciones a la notoriedad una tendencia demasiado plástica». Defendió la causa de la mujer «con unos aires de fronda y con un marimachismo, permítase la palabra, que hacen antipática la pretensión de esa señora, ya de suyo vaga, inoportuna, prematura y precipitada». Y continuaba:

Uno de los pruritos, casi pudiera decirse manía, de la ilustre dama, consiste en el afán de mezclar a hombres y mujeres, de hacerlos andar juntos y codearse en Academias, Ateneos y Universidades. Antes hizo una gran campaña para que las señoras ilustradas pudieran ser académicas de la lengua, y ahora quiere que las jóvenes púberes vayan a cátedra con los aspirantes a bachilleres y aun con los aspirantes a licenciados. Y es más, experimentando su teoría in anima nobili, envía a una hija suya a las aulas del Instituto del Cardenal Cisneros, donde, como es natural, profesores y alumnos la consideran con el respeto que merece una señorita. ${ }^{40}$

Dos días más tarde, publicó otro artículo en el que exaltaba las virtudes de la mujer tradicional, «no redimida por el bachillerado, sino por Cristo». Porque unas cuantas bachilleras y doctoras podrían tener su gracia, especialmente en casa ajena, pero si el ejemplo cundía habría que inventar una nueva carrera: «iLa carrera de mujer como eran casi todas, antes de haber tantas carreras para las mujeres!». El problema era profundo, y la sociedad de la época debía limitarse a plantearlo, sin aspirar a resolverlo:

\footnotetext{
${ }^{40}$ Clarín, «Satura», El Día, 15 de noviembre de 1892. El artículo finalizaba con algunas correcciones de los textos de doña Emilia, que en su memoria sobre la educación de las mujeres había incurrido, entre otros errores, en el de escribir alieni juri en vez de alieni juris. No era la primera vez que ejercía como corrector gramatical, circunstancia de la que se quejaba la escritora en carta a Pérez Galdós (Acosta, Emilia Pardo Bazán, 328).
} 
La educación hombruna de la mujer, que se nos ofrece hoy por hoy (sin más que ciertas variantes formales), no es una solución del gravísimo problema que nuestras generaciones, tan poco adelantadas aún en psicología, sociología y... metafísica (i), deben contentarse con dejar bien planteado.

Ya sé yo que a la señora Pardo Bazán le es muy fácil, y hasta muy agradable, escribir una Memoria aconsejando a todas las damas que sean tan listas y tan instruidas como ella; pero la cuestión que tan sin temor del misterio y de Dios dan por resuelta ciertos pedagogos filantropinescos es mucho más difícil, más honda y más del porvenir que ellos pueden figurarse. ${ }^{41}$

La causa de las mujeres contaba no obstante con algunos defensores. Uno de ellos era el periodista y político Julio Burell, que calificaba de «honda y razonable» la ponencia de Emilio Pardo Bazán y criticaba a quienes recurrían al chiste fácil — tan fácil como los de las suegras-para descalificar las conclusiones del Congreso y a quienes confundían «la noble y honrada independencia de la mujer con la grotesca desenvoltura del marimacho", al tiempo que defendía la necesidad de que las mujeres tuviesen acceso a la educación y a las profesiones para poder enfrentarse a la lucha por la vida, cada vez más despiadada. ${ }^{42}$

\section{LA CÁTEDRA DE DOÑA EMILIA}

Será precisamente Julio Burell, convertido ahora en ministro de Instrucción Pública y Bellas Artes, quien el 7 de enero de 1916 consulte al Consejo de Instrucción pública —en aplicación de lo estipulado en el apartado tercero del artículo 256 de la Ley de Instrucción pública de 1857- sobre la «conveniencia y utilidad» de crear una cátedra de Literatura Contemporánea de las Lenguas neo-latinas en el doctorado de la Facultad de Filosofía y Letras de la Universidad Central. El Consejo contestó que, antes de emitir informe, sería oportuno conocer el parecer de

\footnotetext{
${ }^{41}$ Clarín, «Palique», La Correspondencia de España, 17 de noviembre de 1892.

42 Julio Burell, «¿La mujer libre?», El Heraldo de Madrid, 2 de noviembre de 1892. El autor también subrayaba la crítica suscitada por la figura de la literata: «Se necesita que la escritora se llame, por ejemplo, Emilia Pardo Bazán; es decir, que su estilo literario sea varón y su entendimiento fuera de línea, para que, a regañadientes, y además merced a la lenta persuasión de la costumbre, lleguemos a admirarle y a perdonarle la vocación y el genio».
} 
la facultad a la que estaba destinada la cátedra. ${ }^{43}$ Pero la consulta parece que no fue realizada, o por lo menos no figura en el expediente analizado por Ángeles Quesada Novás.

El 11 de marzo del mismo año, Burell firmó una Real orden en virtud de la cual se creaba la mencionada cátedra, que tendría carácter voluntario, al igual que la de Literatura galaico-portuguesa. Para su provisión se aplicaría, "por esta vez», el procedimiento establecido en los artículos 238 y 239 de Ley Moyano, y su dotación sería la consignada en el artículo 240, aunque solamente se haría efectiva a partir del momento en que fuese incluida en los presupuestos correspondientes. ${ }^{44}$ Según el artículo 238, las cátedras de la Universidad Central correspondientes a estudios posteriores a la licenciatura podrían adjudicarse a «personas de elevada reputación científica, aunque no pertenezcan al Profesorado». El artículo 239 añadía que en tales casos debían presentar candidatos el Real Consejo de Instrucción pública, la facultad implicada y la real academia del ámbito de conocimiento de que se tratase. El gobierno designaría a uno de los candidatos propuestos. ${ }^{45}$

Pero el gobierno ya sabía de antemano el nombre de la persona que sería designada. De hecho, lo sustantivo de esta cátedra - y posiblemente de otras provistas al amparo del artículo 238 - no radicaba tanto en su contenido como en la persona llamada a desempeñarla, y así lo interpretó la prensa desde un primer momento. El 22 de febrero, víspera de la reunión del Consejo de Instrucción pública en la que se trataría sobre su creación, El Globo anticipaba que «el Pleno del Consejo de Instrucción pública propondrá, en su reunión de mañana, el nombramiento de la ilustre escritora condesa de Pardo Bazán, para la cátedra de "Literatura contemporánea de las lenguas neo-latinas", de la Universidad Central», y La Época titulaba: «La condesa de Pardo Bazán, catedrático», e incluso hacía saber a sus lectores que no comenzaría a dar clase hasta el próximo año académico, pero que «en este se propone dar un curso breve, de cuatro o cinco lecciones, sobre Literatura francesa».

\footnotetext{
${ }^{43}$ Ángeles Quesada Novás, «Una meta alcanzada: La cátedra universitaria de Emilia Pardo Bazán», La Tribuna. Cadernos de Estudos da Casa Museo Emilia Pardo Bazán 4 (2006): 43-82. Las citas que se hagan del expediente proceden de este artículo.

${ }^{44}$ Gaceta de Madrid, 15 de marzo de 1916, 620.

${ }^{45}$ Historia de la Educación en España. II De las Cortes de Cádiz a la Revolución de 1868 (Madrid: Ministerio de Educación, 1979), 289.
} 
Seis días más tarde, el diario madrileño La Acción publicó una entrevista titulada «La condesa catedrático». Estaba ilustrada con cuatro fotografías, y en una de ellas figuraba doña Emilia ejerciendo como examinadora en su calidad de consejera de Instrucción pública, cargo para el que había sido propuesta por el conde de Romanones. ${ }^{46}$ Una de las preguntas que Domingo Tejera había incluido en el cuestionario se refería a la profesión que hubiese elegido la escritora en el supuesto de haber nacido varón. Él suponía, o decía suponer, que habría optado por convertirse en catedrático. Y la entrevistada no lo defraudó: «Si hubiese sido hombre, no me formo idea de la profesión que elegiría: supongo que me hubiera doctorado en Filosofía y Letras, aspirando a una cátedra [...]. Y puede que no me muera sin conseguirla». «Horas después — continúa el periodista - daban los periódicos la noticia que el público conoce, y probablemente para el curso próximo, la autora de "Los Pazos de Ulloa" explicará día tras día sus lecciones en el aula de la Universidad». Y Tejera se alegraría de que así fuese, tanto por razones éticas como estéticas —estas no podían faltar tratándose de una mujer:

Hoy, la madurez de los años y la depuración de sus estudios la invisten de una asexualidad moral, a prueba de piropos irrespetuosos de la turba estudiantil. De modo que, además de justo premio al talento, a la cultura, a la laboriosidad perseverante, abona la propuesta del Consejo de Instrucción pública una razón de estética. Porque como homenaje a la mujer, convertida ahora, por méritos de su propio esfuerzo, en catedrático, supongo que los consejeros habrán pensado que a la condesa ha de sentarle bien el birrete con borla de color. ${ }^{47}$

La escritora también daba por supuesto que se trataba de su cátedra. En la crónica de España correspondiente al mes de marzo, publicada en el diario bonaerense La Nación, se felicitaba por la decisión de crear la cátedra, y afirmaba que el Consejo y la Facultad «aprobaron unánimes mi designación». Se recuperaba así — prosigue la autora- una tradición que había caído en desuso, la de que la mujer pudiese enseñar en la uni-

\footnotetext{
${ }^{46}$ En la entrevista se declaraba «romanonista», agradecida como estaba al conde por el nombramiento como consejera. No era romanonista sin embargo en lo referente a la enseñanza del catecismo, aunque consideraba que en esta materia tampoco lo era el propio conde.

${ }^{47}$ La Acción, 28 de febrero de 1916.
} 
versidad, ${ }^{48}$ y ella sería pionera en este ámbito, como también lo había sido en otros:

Me atrevo a indicar, sin asomos de vanidad propia, que el hecho de mi nombramiento para tal cargo envuelve la ruptura de muchas vallas y la desaparición de muchos prejuicios. No he de negar que vengo, desde mi juventud, trabajando para que no encuentre tantos obstáculos la mujer; pero también añadiré que lo hice sin estrépito feminista. No peroré en mítines; casi no escribí, de propósito, sobre el asunto. Mi acción fue personal e individual. Donde pude sentar un precedente favorable no dejé escapar la ocasión. Abrí a la mujer bastantes puertas, y ahora, las de la universidad..$^{49}$

Pero la Facultad no estaba dispuesta a facilitarle el acceso a la cátedra. Su candidatura fue apoyada solamente por ocho profesores (Eloy Bullón, Miguel Morayta, Andrés Ovejero, Cayo Ortega, Emeterio Mazorriaga, José Ramón Mélida, el conde de Las Navas y Elías Tormo, que era el decano), mientras que doce votaron en contra y dos se abstuvieron. En el escrito de remisión del acuerdo al Ministerio se argumentaba que el claustro no había sido capaz de identificar persona alguna «que merced a sus eminentes méritos y excepcional competencia y sin otras pruebas» pueda desempeñar dicha cátedra, porque la enseñanza de la literatura, en cualquiera de sus ramas, presupone «la posesión de métodos y estudios técnicos que es uso reunir bajo el nombre de Filología moderna, frente a la cual no entiende la Facultad que pueda tener la Historia de las Literaturas contemporáneas carácter de Disciplina autónoma y de Ciencia independiente». ${ }^{50} \mathrm{Ni}$ siquiera Pardo Bazán, por «eximia» que fuese, aunque esta concreción no se haga explícita. El corporativismo profesional y el patriotismo sexual pesaban más que los méritos de la candidata.

Otra de las instancias llamadas a pronunciarse - atendiendo al contenido de la cátedra en cuestión—, la Real Academia Española, tampoco

\footnotetext{
${ }^{48}$ Sobre la presencia de las mujeres en las universidades durante períodos históricos anteriores, véase Julia Varela, El nacimiento de la mujer burguesa (Madrid: La Piqueta, 1997).

${ }^{49}$ Emilia Pardo Bazán, La obra periodística completa en «La Nación» de Buenos Aires (1879-1921) (A Coruña: Deputación Provincial da Coruña, 1999), II, 1111, edición de Juliana Sinovas Maté. La crónica fue publicada en La Nación el 27 de abril de 1916.

${ }^{50}$ Quesada Novás, «Una meta alcanzada», 54.
} 
fue favorable a la causa de doña Emilia. Si previamente le había cerrado sus propias puertas por el mero hecho de ser mujer - aunque algún académico se permitió apelar al tamaño de los sillones para justificar la exclusión-, ahora no le abriría las de la universidad, entre otras razones porque si lo hacía quedaría comparativamente malparada. Después de posponer en dos ocasiones el asunto, como señala la profesora Quesada Novás, los académicos registraron en el acta de la sesión celebrada el 13 de abril que no podían proponer a ningún candidato por «no haberse distinguido hasta el presente persona alguna» en los estudios para los que se había creado la cátedra, y en el oficio remitido el día siguiente al ministerio argumentaban que, al ser este tipo de conocimientos «tan comunes de toda persona culta», desconocían "quien acerca de ellos haya hecho públicos trabajos de mérito sobresaliente, ni adecuados para acreditar la necesaria preparación pedagógica». ${ }^{51}$

El ministro solamente consiguió que se pronunciase a favor de su candidata el Consejo de Instrucción pública. Lo hizo, aunque sin gran entusiasmo, el 17 de marzo. Consideraba que la cátedra "pudiera pro-

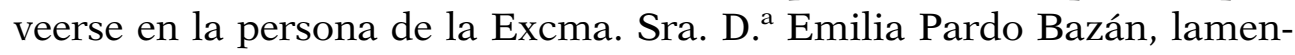
tando no conocer el informe especial de la Facultad de Filosofía y Letras, que habría podido ilustrarle en esta cuestión».52 Afirmación que bien podría traducirse así: si tal informe hubiese sido negativo - y realmente lo fue-, el Consejo tampoco se pronunciaría a favor de quien era una de sus integrantes.

La prensa confiaba en que los organismos que debían intervenir en la provisión de la cátedra serían favorables a la propuesta ministerial. Más todavía, La Época afirmaba que la Academia se vería obligada a modificar su negativa a admitir mujeres en su seno, pues «sería un contrasentido absurdo considerar apta a una mujer para ser catedrática de estudios superiores, y negarle aptitud para ser académica» Los académicos no podían cerrar «la puerta de su casa a la Sabiduría, solamente porque esta tiene nombre de mujer». ${ }^{53}$

\footnotetext{
${ }^{51}$ Quesada Novás, «Una meta alcanzada», 53.

${ }^{52}$ Quesada Novás, «Una meta alcanzada», 52.

${ }^{53}$ ZEDA, «La condesa de Pardo Bazán, catedrática», La Época, 24 de febrero de 1916. Este es uno de los pocos artículos, entre los consultados, en los que se utiliza el genero femenino para referirse a la futura condición de Pardo Bazán.
} 
Una vez que trascendió la votación de la Facultad —los miembros de la Academia serán más discretos-, algunos medios se limitaron a informar de su resultado, especificando el nombre de quienes habían apoyado la propuesta; ${ }^{54}$ otros criticaron abiertamente a los opositores, dudando que estuviesen a la altura de la persona a la que negaban su apoyo ${ }^{55}$ y no faltó quien percibiese la existencia de un «trust» que pretendía impedir a la escritora convertirse en académica o catedrática. ${ }^{56}$ Desde La Lectura Dominical decían sentir el contratiempo que el hecho suponía para «las izquierdas», a las que tantas desgracias afligían en los últimos tiempos, "y lo sentimos doblemente por Colombine [Carmen de Burgos], que había dedicado larga vigilia a resolver el problema gramatical de si doña Emilia, una vez en posesión de su cátedra, se debería llamar "el profesor” o "la profesora”. ¡Cuánta erudición perdida! ${ }^{57}$

La propia Pardo Bazán tuvo que comunicar a los lectores argentinos que había errado en una crónica anterior al afirmar, haciéndose eco de las noticias que le llegaban y de lo que parecía ser el sentir general, que el claustro universitario había apoyado su candidatura. Finalmente, los votos 12 votos negativos superaron a los ocho positivos, aunque estos en realidad ascendían a 10, pues los profesores Hurtado y Bonilla San Martín, ausentes durante la votación, le habían manifestado su adhesión. ${ }^{58}$ Ella había procurado mantenerse al margen del proceso, y así se lo hizo saber a Miguel de Unamuno. No había intrigado en absoluto para conseguir una cátedra que ya tenía previsto crear para ella Canalejas. De haber utilizado los recursos de que disponía, tal vez hubiese sido otro el sentido de la votación. ${ }^{59}$

Pero el ministro estaba dispuesto a seguir adelante con su proyecto, evitando así que la erudición acumulada se perdiese. En su día había conseguido que todas las profesiones relacionadas con el Ministerio de

\footnotetext{
${ }^{54}$ El Imparcial, 19 de abril de 1916.

${ }^{55}$ La Época, 5 de mayo de 1919.

${ }^{56}$ La Acción, 21 de abril de 1916.

${ }^{57}$ La Lectura Dominical, 24 de abril de 1916.

${ }^{58}$ Pardo Bazán, La obra periodística completa en «La Nación», II, 1125-1129; crónica publicada el 2 de julio de 1916.

${ }^{59}$ Carta a Unamuno reproducida en Bravo-Villasante, Vida y obra de Emilia Pardo Bazán, 295-296.
} 
Instrucción Pública y Bellas Artes fuesen accesibles a las mujeres, ${ }^{60} \mathrm{y}$ ahora estaba decidido a que una de ellas - que había aplaudido con entusiasmo la anterior medida ${ }^{61}$ y lamentado que no hubiese sido aprovechada por ninguna mujer durante sus primeros tres años de vigencia ${ }^{62}-$ se incorporase al cuerpo de catedráticos universitarios. Tan pronto como Alfonso XIII regresase de San Sebastián, firmaría el real decreto. Así se hizo el 12 de mayo, dejando constancia de que el nombramiento había sido propuesto por el ministro, de acuerdo con el Consejo y una vez oídas la Facultad y la Academia. ${ }^{63}$ La universidad española ya contaba con su primera catedrática. ${ }^{64}$

Si los recelos corporativos y patriarcales se oponían a los propósitos ministeriales, el feminismo los avalaba. La Época interpretó la decisión como una "concesión al feminismo»;65 la Gaceta de Instrucción Pública y Bellas Artes — propiedad de María de La Rigada - saludaba con entusiasmo el decreto, reclamaba «ipaso al mérito, aunque este haya tenido la menguada idea de hospedarse en la mujer!...», y finalizaba con un «iAArriba los corazones femeninos!!»; 66 Blanca de los Ríos, una de las mejores amigas de la condesa, recordaba, al hacer balance de 1916, que «este año ha dado un gran paso adelante el feminismo en nuestra tierra elevando a la mujer a la cátedra universitaria, en la persona de la gloriosa Condesa de Pardo Bazán». ${ }^{67}$

\footnotetext{
${ }^{60}$ Real orden de 2 de septiembre de 1910, reproducida en Catherine Jagoe, Alda Blanco y Cristina Enríquez de Salamanca, La mujer en los discursos de género (Barcelona: Icaria, 1998), 157.

${ }^{61}$ Pardo Bazán, La obra periodística completa en «La Nación», I, 452-457; crónica publicada el 5 de noviembre de 1910.

${ }^{62}$ «Una habría que lo hiciese, seguramente, y sería yo, pero a mis años no se estudia ya una carrera, porque se hizo otra completa, libre, dentro de la realidad y sin diplomas; y no me es posible contribuir a que no resulte letra muerta el decreto de Burell, que debiera ser la letra más viva, porque ha respondido a una idea de vida y de adelanto modernísimo» (Pardo Bazán, La obra periodística completa en «La Nación», II, 796; crónica publicada el 9 de julio de 1913).

${ }^{63}$ Gaceta de Madrid, 14 de mayo de 1916, 295.

${ }^{64}$ Puede consultarse la semblanza que Consuelo Flecha García nos ofrece de las primeras profesoras universitarias en "Profesoras en la Universidad. El tránsito de las pioneras en España», Arenal. Revista de Historia de las Mujeres 17, no. 2 (2010): 255-297.

${ }^{65}$ «La condesa de Pardo Bazán, catedrático», La Época, 22 de febrero de 1916.

${ }^{66}$ La Gaceta de Instrucción Pública y Bellas Artes, 17 de mayo de 1916.

${ }^{67}$ Blanca de los Ríos Lampérez, «Impresiones literarias de 1916», El Correo Español, 1 de enero de 1917.
} 
Las críticas a Burell se centraron, al menos expresamente, en el procedimiento extraordinario seguido para la provisión de la cátedra. ${ }^{68} \mathrm{En}$ todo caso, la fórmula utilizada era legal, y ya había sido aplicada en otras ocasiones, aunque los beneficiarios habían sido hombres. ${ }^{69} \mathrm{El}$ ministro ni siquiera se vio en la necesidad de recurrir a la discriminación positiva - antes de que tal concepto fuese acuñado-, como había hecho en 1888 el liberal Albareda, cuando concedió prioridad a las maestras para el desempeño de las escuelas primarias mixtas, apelando, al unísono, a argumentos de carácter patriarcal y feminista. ${ }^{70}$ Para la ocasión era suficiente utilizar las posibilidades que la ley ofrecía a ambos sexos, por más que quienes la aprobaron en 1857 seguramente no hubiesen imaginado que el artículo 238 pudiese ser utilizado para designar catedrática a una mujer.

Todos, o casi todos, querían salvar de la crítica a doña Emilia, cuando menos en su condición de escritora. Al ser entrevistado sobre el asunto, José Ortega y Gasset decía ser «admirador» de su obra literaria; consideraba «absurdo» crear una cátedra de Literaturas neo-latinas modernas, entre otras razones porque «no hay una filología de lo contemporáneo», sino un conjunto de «técnicas filológicas», que por lo demás son —al parecer don José estaba interesado en subrayarlo- «sumamente difíciles de dominar»; una vez creada la cátedra, "tengo que declarar, como declaré en la Junta de Facultad correspondiente, que ignoro si hay en España alguna persona conocedora de aquellos métodos y técnicas, gloriosa conquista del siglo XIX, que han transformado la historia literaria de vago centón donde se acumulan sentimientos y anécdotas en una construcción científica». Con todo, si la propuesta hubiese suscitado «el unánime deseo de los amantes de las letras», él la apoyaría, pues la coincidencia de pareceres constituía la mejor garantía contra el posible uso abusivo del artículo 238 de la Ley Moyano:

Ahora bien, en la ocasión presente, ha votado en contra la Facultad universitaria, ha votado en contra la Academia españo-

\footnotetext{
${ }^{68}$ Madrizzy, «Los cestos de Burell», La Correspondencia de España, 24 de febrero de 1916.

${ }^{69}$ La Revista General de Enseñanza y Bellas Artes reproducía los artículos de la Ley Moyano en los que se fundamentaría el nombramiento y aludía a un precedente reciente («La Sra. Pardo Bazán, catedrático», 1 de marzo de 1916).

${ }^{70}$ Narciso de Gabriel, «The entrance of women into the teaching profession in Spain (1855-1940)», History of Education 43, no. 3 (2014): 334-354.
} 
la, cosa que se han olvidado de decir los periódicos; en fin, el acuerdo del Consejo de Instrucción pública se tomó con la asistencia solo de seis miembros y en su dictamen al ministro hacen no pocos reparos, todos los compatibles con su difícil situación. El nombramiento, pues, ha sido fundado en una proposición equívoca, hecha por un organismo tan poco estimado por el Sr. Burell, que se ha apresurado a suprimirlo.

Más contundente fue el profesor Ballesteros, para quien la decisión constituía un nuevo caso de "analfabetismo ministerial», pues su promotor daba por supuesto que «un señor $[$ sic] sin más títulos que una labor periodística de párrafos rotundos y sonoros, con un caudal de liviana y poco costosa erudición, sin base científica en ninguna rama del humano saber, puede disponer a su antojo de las enseñanzas del primer centro docente de España». Andrés Ovejero, que como sabemos había votado a favor de la condesa, optó por la concisión: le parecía muy bien el nombramiento y muy mal el procedimiento. ${ }^{71}$ A lo que Burell bien podría haber argumentado: si el procedimiento hubiese sido otro, el nombramiento no hubiese sido este.

El decano, Elías Tormo, que también era senador, se sintió obligado a defender en la Cámara Alta tanto a doña Emilia como a la Facultad de Filosofía y Letras. Los méritos literarios de la escritora estaban todos prestos a aplaudirlos, y la Facultad se limitó en su dictamen —cuya publicación reclamaba, como se había hecho en casos similares- a especificar los conocimientos filológicos que se precisaban para impartir la materia - y a dar por supuesto que la candidata carecía de ellos, aunque esto último fue omitido por el senador y decano. Sea como fuere, todos estaban encantados con la nueva catedrática, que precisamente ese mismo día, 24 de mayo, a las doce y media, había tomado posesión de su cargo, recibiendo el aplauso de los alumnos que se cruzaron con ella en el claustro. ${ }^{72}$ Tres días más tarde, el ministro Burell, ausente en la anterior sesión del Senado, anunció que se publicarían los dictámenes

\footnotetext{
${ }^{71}$ Las declaraciones de los tres profesores aparecen recogidas, bajo el título de «La Cátedra de Literaturas neo-latinas modernas», en España, 66, 11 de mayo de 1916.

72 Diario de las sesiones de Cortes. Senado, 24 de mayo de 1916, 68-69. El profesor Tormo aludió a que existía un precedente de mujer-catedrática en su Facultad, aunque la cátedra había tenido carácter honorario, el de la Condesa de Guadalcázar, cuyo retrato figuraba en el decanato.
} 
de la Facultad y la Academia, al tiempo que procuraba velar las reservas implícitas manifestadas por una y otra institución acerca de la idoneidad de la condesa para desempeñar la cátedra en cuestión. ${ }^{73}$

De modo que nuestra protagonista unió una nueva dedicación a las que ya tenía. En días alternos, debía apurar la comida para ejercer como catedrática a eso de las cuatro de la tarde. En opinión de una de sus biógrafas, Carmen Bravo-Villasante, el desempeño de este cargo constituía la «suprema aspiración de la maestra que ejerció un magisterio divulgador durante más de cuarenta años». ${ }^{74}$

Los alumnos no abundaban. Inicialmente parece que había unos seis, que se fueron reduciendo hasta llegar a dos. A veces no asistía ninguno, y la condesa se veía obligada a regresar a casa por falta de clientela. Para evitar esta «vergüenza nacional», un viejecito decidió convertirse en oyente asiduo de doña Emilia, pero el viejecito enfermó o falleció. ${ }^{75}$

Uno de sus alumnos fue Pedro Sainz Rodríguez, futuro ministro de Educación del dictador Francisco Franco, que describía así la concurrencia y las clases, de las que decía guardar muy buen recuerdo:

Doña Emilia tuvo que pasar por la preocupación de que, siendo profesora catedrático o catedrática — como se discutió mucho entonces en los periódicos- de literaturas neolatinas, no tenía alumnos; era un catedrático sin alumnos. Esto se remediaba porque las conferencias, que recuerdo eran alternas, debido a la personalidad de doña Emilia, tenían un público ajeno a la universidad. Ella, para asegurarse de todas maneras una concurrencia y no tener que cerrar la cátedra por absoluta falta de oyentes, invitaba a un buen número de muchachas y señoritas de la buena sociedad, amigas suyas; de manera que la cátedra de doña Emilia, hasta que yo llegué, fue una cátedra extrauniversitaria; no había ni un alumno matriculado oficialmente. Por eso, cuando le comentaron que en aquel curso contaba con un alumno oficial, su alegría y asombro no tuvieron límites y me acogió en palmitas, como algo caído del cielo.

\footnotetext{
${ }^{73}$ Diario de las sesiones de Cortes. Senado, 27 de mayo de 1916, 114-115.

${ }^{74}$ Bravo-Villasante, Vida y obra de Emilia Pardo Bazán, 279.

${ }^{75}$ Bravo-Villasante, Vida y obra de Emilia Pardo Bazán, 297-298.
} 
Recuerdo muy bien las clases de doña Emilia. No hablaba; llevaba unas notas muy largas y abundantes que leía, diciendo algunas frases para enlazar las notas entre sí; en realidad era una clase de lectura más que una clase hablada; trataba de literatura francesa y seguía fundamentalmente el manual de Brunetière. ${ }^{76}$

Que la cátedra careciese de alumnos parecía ser un problema de especial relieve, pues mereció la atención tanto del Senado como del Congreso. En sesión celebrada el 6 de abril de 1918, Santiago Mataix y Soler, senador por Zamora, tomó la palabra para reflexionar sobre los problemas de las universidades españolas. Había, por ejemplo, profesores competentísimos que no tenían ni un alumno a quien aleccionar. «Todos nos hemos entusiasmado con el nombramiento de la eximia literata doña Emilia Pardo Bazán para una cátedra en la Universidad Central», añadió el senador. Al ser interrumpido por el vicepresidente, solicitó que se le dejase hablar, por no tener el Senado mejor cosa de la que tratar, y continuó en el uso de la palabra: «La Condesa de Pardo Bazán tiene en su clase una sola alumna, ningún alumno, y además esta alumna es su pariente. (Risas) En cambio, hay cátedras, sobre todo en el preparatorio de la carrera de Medicina, que tienen 600 alumnos con un solo profesor». Seguidamente se centró en el núcleo de su intervención, consistente en denunciar la falta de rigor de la universidad española, particularmente evidente en la Universidad de Murcia, de reciente creación, pero que ya era la segunda España por el número de alumnos, la primera en matrícula libre $(88 \%)$ y la última atendiendo al

\footnotetext{
${ }^{76}$ Quesada Novás, «Una meta alcanzada», 74. Es poco probable que la catedrática se hubiese limitado a leer y a glosar lo escrito por otros autores, ya que era una buena conocedora de la literatura francesa. En 1891 publicó La cuestión palpitante, y más adelante otros tres tomos de crítica a las letras de Francia: La literatura francesa moderna. El Romanticismo (Madrid: V. Prieto y Cía, 1911), La literatura francesa moderna. La Transición (Madrid: V. Prieto y Cía, 1911) y La literatura francesa moderna. El Naturalismo (Madrid: Renacimiento, [1911]). Tenía proyectado publicar un cuarto tomo, sobre la «Decadencia», que no llegó a completar (John W. Kronic, «Entre la ética y la estética: Pardo Bazán ante el decadentismo francés», en Estudios sobre Los pazos de Ulloa, coord. Marina Mayoral (Madrid: Ediciones Cátedra-Ministerio de Cultura, 1989), 163-174). Una selección de sus lecciones universitarias - algunas conservadas en el Archivo de la Real Academia Galega- fueron objeto de una edición póstuma, realizada por Luis Araujo-Costa, bajo el título de El lirismo en la poesía francesa (Madrid: Puello, 1923). Su compilador comenta en el prólogo que la escritora «entregose por completo a la labor de cátedra; descuidó su obra personal; no produjo ya novelas, ni libros de crítica, ni tuvo tiempo que consagrar a sus estudios comenzados sobre Hernán Cortés y la conquista de Méjico. El profesor venció en ella al literato». Este libro será reseñado por Melchor Fernández Almagro, que también se hacía eco del entusiasmo con el que doña Emilia desempeñó la cátedra: «El lirismo en la poesía francesa. Un libro póstumo de la Condesa de Pardo Bazán», La Época, 3 de marzo de 1923.
} 
porcentaje de suspensos (9\%, frente a una media del 15\%). Citó el caso de un alumno - Juan Vitórica y Casuso era su nombre- que había conseguido aprobar 16 asignaturas en una misma convocatoria, lo que era mucho aprobar para una sola vez. Así las cosas, podría parecer que «la penalidad va rondando los Tribunales de exámenes, ya que se rebasan los procedimientos del compadrazgo político». ${ }^{77}$

En el Congreso, la alusión se produjo en el curso de una intervención del ministro Santiago Alba sobre un decreto que trataba acerca de los profesores universitarios jubilados, a los que se proponía reconocer el derecho a percibir el importe de las matrículas de los alumnos que deseasen continuar con ellos sus estudios e investigaciones. En España se procedería como en otros países, cuyas enseñanzas estaban «santificadas, no por la autoridad de la "Gaceta", ni por el mandato del Gobierno, sino por el concurso de la opinión del país y por la asistencia voluntaria de los que toman por profesor a quien consideran más digno de otorgarle su confianza». En ese momento, el diputado Pío Zabala interrumpió al ministro: «La señora Pardo Bazán no tiene ni un solo alumno». Otro diputado, Tomás Elorrieta, advirtió que la materia explicada por la escritora tenía carácter voluntario, y el propio ministro hizo saber que en España había unas 100 cátedras con menos de seis alumnos. Zabala, por su parte, intentó explicar el sentido de su interrupción con otra: «isi la fuerza del argumento es que, siendo una escritora insigne, una maestra eminente, no tenga alumnos!» ${ }^{78}$ Pero dado que no consiguió explicarse debidamente, retomó el asunto en la siguiente sesión, como cuestión previa a su intervención, centrada en criticar los generosos fondos destinados por el Estado a financiar organismos que eran «obra del espíritu de la Institución Libre de Enseñanza», de los que la Junta para Ampliación de Estudios e Investigaciones Científicas constituía un ejemplo paradigmático. Estas fueron sus palabras:

Cuando ayer tuve la impertinencia de interrumpir a S. S. (por lo que le pido mil perdones) diciéndole que una ilustre profesora de la Universidad Central no tiene alumnos en su cátedra, no pretendí causar la menor molestia a la persona a que aludía, sino que, por el contrario, aspiraba a que quedara patentizada esta

\footnotetext{
${ }^{77}$ Diario de las sesiones de Cortes. Senado, 6 de abril de 1918, 75.

${ }^{78}$ Diario de las sesiones de Cortes. Congreso de los Diputados, 13 de mayo de 1918, 1020.
} 
triste realidad: la de que el espíritu de la masa escolar no está preparado para sentir intensamente la vocación científica; realidad que confirma el hecho de que mientras la eminente escritora doña Emilia Pardo Bazán reúne en torno a su figura prestigiosa tantos y tantos oyentes y admiradores en la cátedra del Ateneo, no tiene el mismo éxito en la Universidad a la cual pertenece, en la Universidad en pro de la cual ha consagrado su amor y su entusiasmo como el primero, y en la que vive también quien os habla, en relación de compañerismo cordialísimo con la eminente profesora, recibiendo de tal amistad con el más señalado honor la más legítima satisfacción. (Bien) $)^{79}$

En una de sus últimas entrevistas, el periodista le pidió a doña Emilia, un tanto decaída y resfriada, que le contase algo sobre su cátedra: «Dígame algo...». A lo que la interpelada respondió: «Pues que... ya casi no soy catedrático. No voy a ir... No va nadie a clase. Ni se matriculan siquiera... La daré en el Ateneo o en otro sitio donde vaya público...». Triste respuesta, que su hija intentó mitigar, al igual que había hecho Pío Zabala en el Congreso: «!No van a las [clases] que tienen obligación!... Los estudiantes no van a clase nunca». ${ }^{80}$

En el homenaje que se le tributó en 1922, organizado por una comisión presidida por la duquesa de Alba y que contó con la presencia de «todo el Madrid de las grandes solemnidades», reyes incluidos, el profesor Adolfo Bonilla Sanmartín habló del «brevísimo» desempeño de la cátedra

\footnotetext{
${ }^{79}$ Diario de las sesiones de Cortes. Congreso de los Diputados, 14 de mayo de 1918, 1044-1045.

${ }^{80}$ Entrevista citada por Acosta, Emilia Pardo Bazán, 567. La propia doña Emilia era plenamente consciente del escaso afán de saber que por lo general tenían los universitarios españoles, así como de la escasa calidad de la enseñanza que se les ofrecía. En una conferencia pronunciada en París en 1899 trazaba el siguiente cuadro de la enseñanza universitaria: «Tenemos bastantes Universidades, demasiadas quizá, pero ya no se estudia por lo serio ni existe la fraternidad escolar antigua: la juventud aspira a graduarse y licenciarse de prisa y corriendo, y sepa o no sepa las asignaturas; los estudiantes libres peregrinan de ciudad en ciudad en busca de profesores renombrados por su indulgencia; los de enseñanza oficial se pasan el año pidiendo vacaciones y puntos; todo sirve de pretexto para no asistir a clase; la Navidad cierra durante un mes las aulas. Los métodos de enseñanza son inestables, atrasados y defectuosos; no se aprende más que por libros, sobre cuya calidad habría mucho que decir; ya no se cultivan las humanidades, ya no hay latinistas y todavía no hay ciencia experimental: en la enseñanza, como en todo, España ha perdido las adquisiciones del tiempo viejo y rechazado las del nuevo. Bien sé que podrían citarse excepciones honrosas y hasta gloriosas: acude a mis labios el nombre de Ramón y Cajal: pero la excepción, en nuestra raza, donde el individuo superior apenas influye sobre la colectividad, no sirve más que para confirmar la regla». La España de ayer y la de hoy. (Conferencia de París) (Madrid: Administración de Obras de Emilia Pardo Bazán, 1899), 83-84.
} 
por parte de la escritora. Sus palabras resultan un tanto sorprendentes, atendiendo a la naturaleza y solemnidad del acto. Después de resaltar las «condiciones insuperables para la enseñanza» de la homenajeada, lamentó que no hubiesen sido más fructíferas debido a la falta de alumnos, pero también de un «local apropiado», lo que la obligó a trasladar las clases al Ateneo. ${ }^{81}$

Parece, pues, que ni el profesorado ni el alumnado de la Universidad Central se esmeraron en su acogida a la primera catedrática española. Es lo menos que se puede decir. En todo caso, con estudiantes o sin ellos, la cátedra estaba llamada a figurar en los anales de la historia. La condesa lo sabía, y seguramente era ese su mejor consuelo.

\section{CONSIDERACIONES FINALES}

Aun tratándose de una mujer singular y disfrutando de un estatus privilegiado, la vida y la obra de Emilia Pardo Bazán evidencian las limitaciones y los problemas a los que se enfrentaron las mujeres durante la segunda mitad del siglo XIX y las dos primeras décadas del xx para incorporarse al sistema escolar y al ejercicio de las profesiones, pero también los logros alcanzados en uno y otro escenario, por modestos e incipientes que fuesen.

Frente a un modelo educativo que relativizaba a las mujeres, reduciéndolas a la condición de hijas, esposas y madres, doña Emilia reclamó que fuesen consideradas como seres humanos portadores de un proyecto vital autónomo, o lo que es igual, con sentido en sí mismo y al margen de los hombres. Tal fue la propuesta por ella presentada en el Congreso Pedagógico de 1892, que generó un importante rechazo. Por lo demás, su reivindicación de un acceso igualitario y compartido de uno y otro sexo al sistema educativo - esa obsesión por la mezcla que tanto enojaba a Clarín- no mereció la aprobación de los congresistas, que optaron por la creación de centros específicos para las mujeres. Tampoco aceptaron el derecho de estas al desempeño de todas las profesiones, restringiendo el abanico de posibilidades a aquellas para las que se consideraban más aptas.

Una de ellas era la enseñanza, aunque solamente en el nivel infantil —escuelas de párvulos en la terminología de la época- y primario.

\footnotetext{
${ }^{81}$ La Acción y La Época, 12 de junio de 1922.
} 
El acceso al profesorado universitario suscitó, por el contrario, fuertes resistencias, que padeció nuestra protagonista en primera persona. Consiguió vencerlas contando con el apoyo de hombres que, como Julio Burell, apostaban por una cierta emancipación y un cierto reconocimiento de los derechos de las mujeres. Se convirtió así en pionera en el ámbito de la docencia universitaria, como también lo había sido en otros.

\section{Nota sobre el autor}

Narciso de Gabriel es profesor de Historia de la Educación en la Universidad de A Coruña. Sus libros más recientes son Escolantes e escolas de ferrado (Vigo: Xerais, 2001); Ler e escribir en Galicia. A alfabetización dos galegos e das galegas nos séculos XIX e XX (A Coruña: Servizo de Publicacións da UDC, 2006); Elisa e Marcela. Alén dos homes (Vigo: NigraTrea, 2008; en castellano, Barcelona: Libros del Silencio, 2010) y 25 anos de UDC: A universidade na Coruña e Ferrol (A Coruña, Servizo de Publicacións da UDC, 2015). Ha publicado artículos en revistas como Historia de la Educación, Historia y Memoria de la Educación, History of Education, Paedagogica Historica, Revista de Educación, Ricerche Pedagogiche, Revista Galega de Educación or Eduga. Revista Galega do Ensino. En la actualidad dirige Sarmiento. Anuario Galego de Historia da Educación.

\section{Referencias}

Acosta, Eva. Emilia Pardo Bazán. La luz en la batalla. Barcelona: Lumen, 2007. AlBerdi, Inés. Emilia Pardo Bazán. Madrid: EILA Editores, 2013.

Ballarín Domingo, Pilar. «Bertha Wilhelmi y su defensa de la aptitud de la mujer para todas las profesiones». Arenal. Revista de Historia de las Mujeres 5, no. 1 (1998): 191-217.

- La educación de las mujeres en la España contemporánea (siglos XIX y XX). Barcelona: Síntesis, 2001.

- «Entre ocupar y habitar. Una revisión historiográfica sobre Mujeres y Universidad en España». Arenal. Revista de Historia de las Mujeres 17, no. 2 (2010): 223-254.

Batanaz Palomares, Luis. La educación española en la crisis de fin de siglo (Los Congresos pedagógicos del siglo XIX). Córdoba: Diputación Provincial de Córdoba, 1982. 
Bravo-Villasante, Carmen. Vida y obra de Emilia Pardo Bazán. Madrid: Magisterio Español, 1973.

CAPEl Martínez, Rosa María. «La apertura del horizonte cultural femenino: Fernando de Castro y los Congresos pedagógicos del siglo XIX». En Mujer y Sociedad en España (1700-1975), editado por M. ${ }^{a}$ Ángeles Duran y Rosa M. ${ }^{\mathrm{a}}$ Capel, 109-145. Madrid: Ministerio de Cultura, 1982.

Сово, Rosa. Fundamentos del patriarcado moderno. Jean Jacques Rousseau. Madrid: Cátedra, 1995.

Cook, Teresa A. «Emilia Pardo Bazán y la educación como elemento primordial en la liberación de la mujer». Hispania 60, no. 2 (1977): 259-265.

Ezama GIL, Ángeles. «La vocación pedagógica de Emilia Pardo Bazán». Moenia 18 (2012): 417-437.

Faus, Pilar. Emilia Pardo Bazán. Su época, su vida, su obra. A Coruña: Fundación Pedro Barrié de la Maza, 2003.

Fernández PozA, Milagros. «El debate educativo de finales del ochocientos y el Congreso Pedagógico Hispano-Portugués-Americano». Cuadernos de Historia Contemporánea, vol. extraordinario (2007): 71-82.

Flecha García, Consuelo. Las primeras universitarias en España. Madrid: Narcea, 1996.

- «Lo que piensan las mujeres acerca de su educación». Historia de la Educación. Revista Interuniversitaria 26 (2007): 395-435.

- «Profesoras en la Universidad. El tránsito de las pioneras en España». Arenal. Revista de Historia de las Mujeres 17, no. 2 (2010): 255-297.

GABRIEL, Narciso de. Leer, escribir y contar. Escolarización popular y sociedad en Galicia (1875-1900). Sada-A Coruña: Ediciós do Castro, 1990.

- "A educación das mulleres no século XIx: exclusión, dependencia e autonomía». Sarmiento. Anuario Galego de Historia da Educación 17 (2013): 7-35.

- «The entrance of women into the teaching profession in Spain (1855-1940)». History of Education 43, no. 3 (2014): 334-354.

Historia de la Educación en España. II De las Cortes de Cádiz a la Revolución de 1868. Madrid: Ministerio de Educación, 1979.

KRONIC, John W. «Entre la ética y la estética: Pardo Bazán ante el decadentismo francés». En Estudios sobre Los pazos de Ulloa, editado por Marina Mayoral, 163-174. Madrid: Ediciones Cátedra-Ministerio de Cultura, 1989.

Mandado Gutiérrez, Ramón Emilio, Juana Sánchez-Gey Venegas y Benito MADARIAGA DE LA CAMPA. La Institución Libre de Enseñanza y la Asociación para la Enseñanza de la Mujer. Bosquejo histórico de la educación española del siglo XIX. Santander: UIMP, 2011.

Mayoral, Marina. "Estudo introdutorio» a La educación del hombre y de la mujer. La dama joven. Memorias de un solterón de Emilia Pardo Bazán, 11-80. Santiago de Compostela: Sotelo Blanco Edicións, 2006. 
Pardo Bazán, Emilia. La mujer española y otros escritos. Madrid: Cátedra, 1999. (ed. Guadalupe Gómez-Ferrer).

- La obra periodística completa en «La Nación» de Buenos Aires (1879-1921). A Coruña: Deputación Provincial da Coruña, 1999.

Penas, Ermitas. Clarín, crítico de Emilia Pardo Bazán. Santiago de Compostela: Universidade de Santiago de Compostela, 2003.

- «Giner de los Ríos en la formación de Emilia Pardo Bazán: a propósito de un epistolario». La Tribuna. Cadernos de Estudos da Casa Museo Emilia Pardo Bazán 2 (2004): 103-129.

QuesAda Novás, Ángeles. «Una meta alcanzada: La cátedra universitaria de Emilia Pardo Bazán». La Tribuna. Cadernos de Estudos da Casa Museo Emilia Pardo Bazán 4 (2006): 43-82.

Rousseau, Jean-Jacques. Emilio o De la Educación. Barcelona: Fontanella, 1973. (1. ${ }^{\mathrm{a}}$ ed. 1762).

Varela, José Luis. «E. Pardo Bazán: epistolario a Giner de los Ríos». Boletín de la Real Academia de la Historia CXCVIII, cuadernos II y III (2001): 327-390 y 439-506.

VARELA, Julia. El nacimiento de la mujer burguesa. Madrid: La Piqueta, 1997.

VÁzouez RamiL, Raquel. Mujeres y educación en la España contemporánea. La Institución Libre de Enseñanza y la Residencia de Señoritas de Madrid. Madrid: Akal, 2012.

Wollstonecraft, Mary. Vindicación de los Derechos de la Mujer. Madrid: Cátedra, 1994 (1. a ed. 1792). 